\title{
ESTABELECIMENTO DE ESPÉCIES FLORESTAIS NATIVAS POR MEIO DE SEMEADURA DIRETA PARA RECUPERAÇÃO DE ÁREAS DEGRADADAS ${ }^{1}$
}

\author{
Paula Luíza Santos², Robério Anastácio Ferreira³ ${ }^{3}$ Alexsandro Guimarães de Aragão ${ }^{3}$, Luise Andrade \\ Amaral $^{4}$ e Andreza Santos Oliveira ${ }^{3}$
}

\begin{abstract}
RESUMO - Este trabalho foi realizado com o objetivo de avaliar a utilização da semeadura direta e a influência de um protetor físico sobre o estabelecimento de espécies florestais nativas em uma área com pastagem e outra com agricultura. O experimento foi executado no Município de São Cristóvão, SE (1055’20"S e 37¹2’00"W), em delineamento em blocos casualizados, em esquema fatorial, com três repetições. Foram utilizadas sementes de Erythrina velutina Wild., Bowdichia virgilioides Kunth., Guazuma ulmifolia Lam., Machaerium aculeatum Raddi, Lonchocarpus sericeus (Poir) DC. e Sapindus saponaria L. As avaliações feitas em campo foram: emergência, sobrevivência e desenvolvimento inicial das mudas das espécies (altura e diâmetro). Com relação à emergência e sobrevivência de plântulas, houve diferença significativa entre os dois ambientes, com melhores resultados no subsistema agricultura. Considerando o desenvolvimento das espécies, E. velutina destacou-se das demais por ter apresentado as maiores médias de altura e diâmetro nas duas áreas, em ambos os tratamentos. A semeadura direta foi viável na recuperação de áreas degradadas com espécies florestais nativas, nos ambientes estudados.
\end{abstract}

Palavras-chave: Sementes de espécies florestais, Plantio direto e Protetor físico de germinação.

\section{ESTABLISHMENT OF NATIVE SPECIES BY DIRECT SEEDING FOR RESTORATION OF DEGRADED AREAS}

\begin{abstract}
The objective of this work was to evaluate the use of direct sowing and the influence of a physical protector on establishment of native species, in a pasture area and on a crop area as well. The experiment

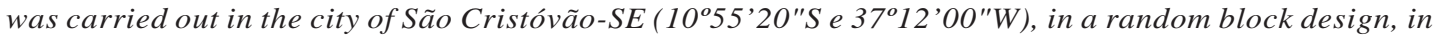
a factorial design with three replicates. Seeds of Erythrina velutina Wild., Bowdichia virgilioides Kunth., Guazuma ulmifolia Lam., Machaerium aculeatum Raddi, Lonchocarpus sericeus (Poir) DC. and Sapindus saponaria L. were used. Field evaluatinons consisted on the following: emergence, survival and early development of the species (height and diameter). With regard to the emergence and seedlings survival, there was significant difference between the two studied environments, in which the subsystem agriculture showed the best results. Considering the development of species in the field, E. velutina stood out due to the higher values of height and diameter in both areas, in both treatments. Direct sowing was feasible in the recovery of degraded areas, with the use of native species, in the study areas.
\end{abstract}

Keywords: Forest species seeds, Direct sowing, Physical protector of germination and No-tillage system.

\footnotetext{
${ }^{1}$ Recebido em 22.09.2010 e aceito para publicação em 29.03.2012

${ }^{2}$ Centro Comunitário de Formação em Agropecuária Dom José Brandão de Castro. E-mail: <p.luizas@gmail.com>.

${ }^{3}$ Universidade Federal de Sergipe, UFS, Brasil. E-mail: <raf@ufs.br>, <sandrofloresta@yahoo.com.br>.

${ }^{4}$ Programa de Pós-Graduação em Ciência Florestal pela Universidade Federal dos Vales do Jequitinhonha e Mucuri, UFVJM, Brasil.E-mail: <andrade.luise@hotmail.com>.
} 


\section{INTRODUÇÃO}

A falta de planejamento no uso dos recursos naturais tem resultado na degradação dos ecossistemas florestais. Diante disso, nos últimos anos surgiram vários programas visando à recuperação desses ambientes, os quais consideram vários fatores, entre eles o ecológico, o silvicultural, o social e, especialmente, o econômico. Daí a preocupação em desenvolver técnicas que visem reduzir ao máximo os custos com a implantação de espécies florestais nativas para a recuperação de ecossistemas fortemente antropizados ou degradados.

Entre as técnicas que se demonstram promissoras no processo de recuperação ambiental, destaca-se a semeadura direta (SANTOS JÚNIOR et al., 2004; FERREIRA et al., 2007; FERREIRA et al., 2009), que, além de reduzir custos, elimina toda a fase de produção de mudas em viveiro. É um procedimento barato e versátil de reflorestamento que pode ser utilizado na maioria das condições de sítios e, principalmente, em situações onde a regeneração natural e, ou, o plantio de mudas não podem ser realizados, com resultados satisfatórios em áreas degradadas de difícil acesso e grande declividade(BARNETT; BAKER, 1991; MATTEI, 1995a).

No Brasil, vários autores têm desenvolvido e aperfeiçoado essa técnica na tentativa de possibilitar o seu uso, tanto na recuperação de ecossistemas quanto na implantação de povoamentos para fins econômicos. Em diversas experiências, os resultados foram satisfatórios na recuperação de matas ciliares (SANTOS JÚNIOR et al., 2004; FERREIRA et al., 2009) e na implantação de povoamentos de Pinus sp. (MATTEI, 1995a; MATTEI et al., 2001).

O plantio direto de sementes florestais pode ser utilizado tanto para a introdução de espécies pioneiras em áreas sem cobertura vegetal quanto de espécies secundárias tardias e clímax no enriquecimento de florestas secundárias; porém, a germinação de sementes das espécies nativas é bastante irregular, com a predominância de poucas espécies, sendo necessária a reposição das sementes nos locais onde ocorreram falhas na semeadura (KAGEYAMA; GANDARA, 2004). Nesse aspecto, o uso de tratamentos para superação da dormência pode auxiliar no processo germinativo, contribuindo para rápida germinação e recobrimento mais efetivo e uniforme do solo (AERTS et al., 2006; FERREIRA et al., 2007).
Com o intuito de viabilizar o processo de semeadura direta, vários autores testaram o uso de protetores físicos de germinação, visando à redução da taxa de herbivoria e ao aumento da temperatura e umidade da camada superficial do solo (SANTOS JÚNIOR et al., 2004; FERREIRA et al., 2007). De acordo com Mattei et al. (2001), o uso de protetores físicos tem como objetivo propiciar melhorias na germinação das sementes e sobrevivência das mudas em campo, criando um microambiente para o seu desenvolvimento. Isso além de impedir a movimentação das sementes no solo em épocas de fortes chuvas, mantém a profundidade de semeadura e facilita a emergência, o que dificulta o ataque de inimigos naturais (MATTEI, 1995b).

Vale ressaltar que há mais riscos da sobrevivência das mudas ser mais baixa com a semeadura direta do que com o plantio de mudas. Porém, a semeadura é uma das técnicas mais promissoras no processo de recuperação de áreas degradadas e ciliares, especialmente quando um dos objetivos é a redução de custos.

Desse modo, objetivou-se avaliar a utilização da semeadura direta e a influência de um protetor físico no estabelecimento de espécies florestais nativas, em dois subsistemas com diferentes tipos de uso do solo, localizados em um agroecossistema do Município de São Cristóvão, Sergipe.

\section{MATERIAL E MÉTODOS}

\section{1. Área de estudo}

O experimento foi realizado no Campus Rural da Universidade Federal de Sergipe, localizado no Município de São Cristóvão, SE (1055’20"S e 37¹2’00"W). O clima da região é do tipo As, de acordo com a classificação de Köppen (tropical chuvoso com verão seco). O período chuvoso ocorre entre os meses de abril e agosto, sendo a temperatura média de $25,5^{\circ} \mathrm{C}$, a umidade relativa do ar média de $75 \%$ e a precipitação média anual de $1.200 \mathrm{~mm}$ (MELO et al., 2006).

A semeadura ocorreu em dois locais distintos, distantes aproximadamente $350 \mathrm{~m}$ : a) subsistema de pastagem: área de 1,275 ha, coberta com plantas invasoras e herbáceas e utilizada como pasto para alguns animais (bovinos, ovinos e equinos); e b) subsistema de agricultura: área com 0,594 ha, anteriormente utilizada para produção de cana-de-açúcar, que foi substituída 
pelo cultivo de outras culturas agrícolas (macaxeira e batata) e antes da implantação do experimento se encontrava em um pousio de dois anos.

O solo no subsistema pastagem é classificado como Argissolo Vermelho-Amarelo Distrófico (EMBRAPA, 1999), cujas análises química e física determinaram $\mathrm{pH}$ em $\mathrm{H}_{2} \mathrm{O}$ de 5,04; 7,71 g/ $\mathrm{dm}^{3}$ de matéria orgânica; 1,20 ppm de P; 0,75 cmolc/ $\mathrm{dm}^{3}$ de Ca; $0,60 \mathrm{cmolc} / \mathrm{dm}^{3}$ de Mg; 0,07 cmolc/dm ${ }^{3}$ de K; 0,037 cmolc/ $\mathrm{dm}^{3}$ de Na; 2,23 cmolc/ $\mathrm{dm}^{3}$ de $\mathrm{H}+\mathrm{Al} ; 90,70 \%$ de areia; 5,83\% de silte; e 3,47\% de argila. No subsistema agricultura, o solo é classificado como Neossolo Flúvico Psamítico (EMBRAPA, 1999), no qual os resultados das análises química e física foram os seguintes: $\mathrm{pH}$ em $\mathrm{H}_{2} \mathrm{O}$ de 4,90; 17,00 g/dm³ de matéria orgânica; 4,10 ppm de P; 0,58 cmolc $/ \mathrm{dm}^{3}$ de Ca; 0,75 cmolc/ $\mathrm{dm}^{3} \mathrm{de} \mathrm{Mg}$; $0,05 \mathrm{cmolc} / \mathrm{dm}^{3} \mathrm{de} \mathrm{K} ; 0,042 \mathrm{cmolc} / \mathrm{dm}^{3} \mathrm{de} \mathrm{Na}$; $1,82 \mathrm{cmolc} / \mathrm{dm}^{3}$ de $\mathrm{H}+\mathrm{Al} ; 80,45 \%$ de areia; $12,00 \%$ de silte; e $7,55 \%$ de argila.

\subsection{Espécies utilizadas}

As espécies selecionadas são arbóreas, de ocorrência natural no Estado de Sergipe e com características potenciais para serem utilizadas em trabalhos de recuperação de áreas degradadas, as quais estão relacionadas na Tabela 1 .

A colheita dos frutos foi realizada em diversas matrizes situadas no Estado, considerando-se as populações das espécies selecionadas. O período de colheita ocorreu entre os meses de janeiro a abril de 2008, no caso das espécies $B$. virgilioides, E. velutina e $M$. aculeatum. Os frutos de $L$. sericeus foram colhidos no período de setembro a novembro de 2007. A $S$. saponaria teve os frutos colhidos entre os meses de novembro de 2007 e março de 2008. No caso da G ulmifolia, a colheita foi realizada no período de janeiro a março de 2008. Após a extração, as sementes foram acondicionadas em sacos plásticos transparentes impermeáveis e armazenadas em câmara fria (6-9 ${ }^{\circ} \mathrm{C}$ e $60-65 \%$ de umidade relativa), onde permaneceram até a instalação do experimento.

\subsection{Análise das sementes}

Antes da implantação do experimento no campo foi realizada a análise das características físicas e da viabilidade dos lotes das sementes, no Laboratório de Sementes do Departamento de Ciências Florestais (UFS), tomando-se como base as recomendações contidas nas Regras para Análise de Sementes (BRASIL, 2009) para outras espécies arbóreas. Quanto às características físicas, foram determinados o grau de umidade (Termobalança Determinadora de Umidade - Top Ray), o peso de 1.000 sementes e o número de sementes por quilograma.

As sementes de B. virgilioides, G. ulmifolia e S. saponaria foram imersas em ácido sulfúrico por 10, 50 e 60 min, respectivamente, enquanto as de E. velutina sofreram escarificação mecânica, com o auxílio de lixa, até a parte do cotilédone tornar-se visível, pelo fato de as sementes serem dormentes, segundo as recomendações de Davide et al. (1995) e Davide e Silva (2008).

Na determinação da viabilidade, foi realizado o teste em câmara de germinação (BOD), com temperatura de $25{ }^{\circ} \mathrm{C}$, sob luz contínua, durante o período de 45 dias. As sementes foram semeadas em bandejas plásticas sobre o substrato de areia (lavada, peneirada e esterilizada em estufa a $120^{\circ} \mathrm{C}$, por $24 \mathrm{~h}$ ), em quatro repetições

Tabela 1 - Relação das espécies utilizadas na implantação da semeadura direta nos dois subsistemas, localizados no Município de São Cristóvão, SE.

Table 1 - List of species used in the implantation of the direct sowing in the two subsystems, located in the city of São Cristovão, SE.

\begin{tabular}{lllc}
\hline Nome científico & Nome vulgar & Família & GE \\
\hline Bowdichia virgilioides Kunth. & Sucupira-preta & Leg. Papilionoideae & P \\
Erythrina velutina Willd. & Mulungu & Leg. Papilionoideae & P \\
Guazuma ulmifolia Lam. & Mutamba & Sterculiaceae & P \\
Lonchocarpus sericeus (Poir) D.C. & Falso-Ingá & Leg. Papilionoideae & CL \\
Machaerium aculeatum Raddi & Mau-vizinho & Leg. Papilionoideae & P \\
Sapindus saponaria L. & Saboneteira & Sapindaceae & CL \\
\hline
\end{tabular}

Grupo ecológico (GE): P - pioneira; e CL clímax exigente em luz (OLIVEIRA-FILHO et al., 1995). 
de 25 sementes de cada espécie. As avaliações foram realizadas a cada dois dias, considerando-se como critério de avaliação as plântulas com todas as estruturas normais. Para manter as sementes hidratadas, foi feita a reposição de água sempre que necessário.

\subsection{Implantação e condução do experimento em campo}

O preparo das áreas foi realizado de forma mecanizada, com a limpeza do terreno por meio de roçagem, para remoção das plantas invasoras; aração a 0,30 m de profundidade; e gradagem cruzada, para descompactação da camada superficial do solo e nivelamento do terreno. No subsistema de pastagem foi instalada cerca de arame farpado para evitar a entrada de animais e o pisoteio das plantas em desenvolvimento.

A semeadura foi realizada em covas $(0,30 \times 0,30$ x 0,30 m), em espaçamento de 1,5 x 1,5 m, na primeira semana de maio de 2009. O delineamento utilizado foi em blocos casualizados (DBC), em esquema fatorial $2 \times 2 \times 6$ (ambiente, protetor físico e espécies), com três repetições. Em cada bloco experimental havia 84 pontos de semeadura, totalizando-se 252 covas por área. Em cada subsistema foi utilizada uma área de $495 \mathrm{~m}^{2}$. As sementes de cada espécie foram semeadas numa linha de plantio com sete plantas para cada tratamento (presença ou ausência de protetor físico).

A densidade utilizada de sementes variou entre as espécies, sendo para B. virgilioides, E. velutina e $S$. saponaria cinco sementes por cova e 10 para $G$. ulmifolia, L. sericeus e M. aculeatum. Vale ressaltar que a densidade das sementes em campo variou entre as espécies, devido aos resultados obtidos no teste de germinação em laboratório. Antes da semeadura foi realizado tratamento para superação da dormência das sementes, conforme descrito no item 2.3.

Para o tratamento presença de protetor físico, foram utilizados copos plásticos transparentes de $750 \mathrm{~mL}$, colocados sobre os pontos semeados e enterrados a uma profundidade de aproximadamente $2 \mathrm{~cm}$, sendo removidos 90 dias após a semeadura. Depois da remoção dos protetores físicos, foi feito o desbaste das plântulas, deixando-se apenas uma por cova e dando início à avaliação das características de crescimento (altura e diâmetro do colo). Para a medição da altura foi utilizada uma régua graduada, sendo o diâmetro do colo medido com o auxílio de um paquímetro plástico analógico com capacidade de $150 \mathrm{~mm} / 6$ polegadas e graduação de $0,05 \mathrm{~mm}$.
Por ocasião da semeadura, foi realizada a adubação inicial com superfosfato simples (200 g) e aos 60 dias após a implantação do experimento, a adubação de cobertura, utilizando-se 150 g de NPK, na formulação de 20:10:20. O controle de plantas invasoras (manual) e de formigas-cortadeiras (iscas granuladas) foi realizado durante todo o experimento.

\subsection{Análises estatísticas}

Para a emergência de plântulas e sobrevivência das mudas em campo, foram utilizadas as médias transformadas em arcosseno de raiz quadrada de $\mathrm{x} / 100$, enquanto para a análise das características de crescimento, a média dos dados originais. As análises foram feitas no programa SISVAR (FERREIRA, 2006) e as médias, comparadas pelo teste de Scott-Knott a 5\%.

\section{RESULTADOS}

\subsection{Análise das sementes}

Os resultados referentes ao grau de umidade, peso de 1.000 sementes, número de sementes por kg e viabilidade encontram-se na Tabela 2. Quanto ao grau de umidade, as sementes de $M$. aculeatum apresentaram os maiores teores de água (10,19\%), enquanto as demais espécies mostraram valores entre 4-6\%. O peso de 1.000 sementes e o número de sementes por kg variaram entre as espécies, com $B$. virgilioides, G. ulmifolia e $M$. aculeatum apresentando número relativamente alto de sementes por $\mathrm{kg}$. Os resultados do teste de germinação indicaram que houve diferença significativa entre as espécies, com relação à porcentagem de sementes germinadas e à quantidade de plântulas normais.

\subsection{Emergência de plântulas e sobrevivência das mudas em campo}

Nos dois subsistemas com semeadura direta houve diferença significativa na porcentagem de emergência de plântulas (Tabela 3). No subsistema de agricultura, observaram-se as melhores médias de emergência (54\%), em comparação com o subsistema de pastagem (28\%). A emergência de plântulas oriundas de sementes das espécies E. velutina, B. virgilioides, S. saponaria e G. ulmifolia foi diferente, considerando-se as duas áreas, com maiores médias no subsistema agricultura, ao contrário de $L$. sericeus e $M$. aculeatum, para as quais não ocorreram diferenças significativas em ambos os ambientes. 
Tabela 2 - Teor de água, peso de 1.000 sementes, número de sementes por quilograma e porcentagem de sementes que emitiram radícula e plântulas normais das espécies selecionadas.

Table 2 - Water content, one thousand seed weight, number of seeds per kilogram and root emergence of seeds and normal seedlings percentage of selected species.

\begin{tabular}{|c|c|c|c|c|c|}
\hline Espécies & Umidade (\%) & $\begin{array}{c}\text { Peso de } 1.000 \\
\text { sementes }(\mathrm{g})\end{array}$ & $\mathrm{N}^{o}$ de sementes $/ \mathrm{kg}$ & $\begin{array}{l}\text { Emissão de } \\
\text { radícula (\%) }\end{array}$ & $\begin{array}{c}\text { Plântulas normais } \\
(\%)\end{array}$ \\
\hline Erythrina velutina & 4,91 & 427,33 & 2.340 & $98 \mathrm{a}$ & $93 \mathrm{a}$ \\
\hline Bowdichia virgilioides & 4,64 & 18,14 & 55.127 & $94 \mathrm{a}$ & $98 \mathrm{a}$ \\
\hline Guazuma ulmifolia & 5,37 & 5,93 & 168.634 & $66 \mathrm{~b}$ & $91 \mathrm{a}$ \\
\hline Sapindus saponaria & 5,67 & 735,32 & 1.360 & $62 \mathrm{c}$ & $86 \mathrm{~b}$ \\
\hline Lonchocarpus sericeus & 5,29 & 365,61 & 2.375 & $41 \mathrm{c}$ & $84 \mathrm{~b}$ \\
\hline Machaerium aculeatum & 10,19 & 60,66 & 16.485 & $19 \mathrm{~d}$ & $97 \mathrm{a}$ \\
\hline
\end{tabular}

Médias seguidas pela mesma letra nas colunas não diferem entre si, pelo teste de Scott-Knott a 5\% de probabilidade.

Tabela 3 - Emergência de plântulas oriundas de sementes das espécies estudadas até os 90 dias após a semeadura, nos dois subsistemas, situados no Município de São Cristóvão, SE. CP com protetor e SP sem protetor.

Table 3 - Seedlings emergence from seeds of the species, until 90 days after sowing, in both subsystems located in the city of Sãoo Cristovao-SE. CP - with physical protector; SP - without physical protector.

\begin{tabular}{|c|c|c|c|c|}
\hline \multirow{2}{*}{ Espécies } & \multicolumn{2}{|c|}{ Subsistema pastagem } & \multicolumn{2}{|c|}{ Subsistema agricultura } \\
\hline & $\mathrm{CP}$ & SP & $\mathrm{CP}$ & SP \\
\hline Erythrina velutina & $57 \mathrm{aA}$ & $78 \mathrm{aA}$ & $99 \mathrm{aA}$ & $85 \mathrm{aA}$ \\
\hline Bowdichia virgilioides & $16 \mathrm{bA}$ & $0 \mathrm{cA}$ & $96 \mathrm{aA}$ & $39 \mathrm{bB}$ \\
\hline Sapindus saponaria & $40 \mathrm{aA}$ & $43 \mathrm{bA}$ & $79 \mathrm{aA}$ & $65 \mathrm{aA}$ \\
\hline Guazuma ulmifolia & $27 \mathrm{bA}$ & $7 \mathrm{cA}$ & $52 \mathrm{bA}$ & $26 \mathrm{bA}$ \\
\hline Lonchocarpus sericeus & $50 \mathrm{aA}$ & $6 \mathrm{cB}$ & $45 \mathrm{bA}$ & $44 \mathrm{bA}$ \\
\hline Machaerium aculeatum & $7 \mathrm{bA}$ & $1 \mathrm{cA}$ & $15 \mathrm{cA}$ & $2 \mathrm{cA}$ \\
\hline \multirow{2}{*}{ Média } & $33 \mathrm{~A}$ & $23 \mathrm{~A}$ & $64 \mathrm{~A}$ & $44 \mathrm{~B}$ \\
\hline & \multicolumn{2}{|c|}{$280 \mathrm{~B}$} & \multicolumn{2}{|c|}{$54 \mathrm{~A}$} \\
\hline
\end{tabular}

Médias seguidas pela mesma letra não diferem entre si, pelo teste de Scott-Knott a 5\% de probabilidade.

Letras minúsculas na vertical comparam as espécies para cada protetor (CP/SP), em cada ambiente.

Letras maiúsculas na horizontal comparam protetor para cada espécie, em cada ambiente.

Letras maiúsculas na horizontal comparam protetor, em cada ambiente.

Considerando-se a influência do protetor físico, no subsistema de pastagem não houve diferença significativa entre a presença e ausência do protetor na emergência, com exceção de $L$. sericeus, cujo comportamento da emergência foi contrário àquele das demais espécies. No subsistema agricultura, a utilização do protetor influenciou na emergência de plântulas em campo. Porém, apesar de o protetor ter influenciado na emergência, não houve diferença significativa nas espécies E. velutina, S. saponaria, G. ulmifolia, L. sericeus e $M$. aculeatum.

A sobrevivência das mudas também diferiu estatisticamente entre os dois ambientes (Tabela 4). Nas espécies E. velutina, S. saponaria e L. sericeus, constataram-se os maiores níveis de sobrevivência, não diferindo estatisticamente entre as áreas. A sobrevivência de mudas de G. ulmifolia também foi semelhante nos dois subsistemas, porém os valores foram baixos. Com relação a $M$. aculeatum e $B$. virgilioides, observaram-se diferenças no número de plantas vivas nos dois ambientes.

Quanto à eficiência do protetor físico na sobrevivência das mudas em campo, no subsistema pastagem não houve diferença significativa entre os tratamentos, com exceção de $S$. saponaria, para a qual se registrou o maior número de plântulas vivas na parcela com protetor (90\%). No subsistema agricultura, o tratamento com protetor físico influenciou no 
estabelecimento das mudas. Contudo, apesar de o protetor ter auxiliado na sobrevivência das mudas, não houve diferença significativa nas espécies E. velutina, S. saponaria, L. sericeus e M. aculeatum.

\subsection{Desenvolvimento inicial das espécies}

Na Tabela 5 estão os valores referentes às médias das alturas das plantas, pelos quais se observou que não houve diferença significativa entre os ambientes estudados. O mesmo comportamento foi presenciado nos tratamentos com e sem protetor físico em cada área.

Com relação à média de altura entre as espécies em cada ambiente, no subsistema pastagem, nas parcelas com protetor físico, E. velutina e G. ulmifolia diferiram estatisticamente das demais espécies, enquanto no tratamento sem protetor apenas em E. velutina se constatou maior significância. Vale destacar que a altura média de plantas de $E$. velutina nas parcelas sem protetor físico foi maior que naquelas com protetor. No subsistema

Tabela 4 - Sobrevivência das mudas das espécies estudadas até os 90 dias após a semeadura, nos dois subsistemas, localizados no Município de São Cristóvão, SE. CP - com protetor e SP sem protetor.

Table 4 - Seedlings survival of the studied species, until 90 days after sowing in both subsystems, located in the city of São Cristovao-SE. CP with physical protector; SP without physical protector.

\begin{tabular}{|c|c|c|c|c|}
\hline \multirow{2}{*}{ Espécies } & \multicolumn{2}{|c|}{ Subsistema pastagem } & \multicolumn{2}{|c|}{ Subsistema agricultura } \\
\hline & $\mathrm{CP}(\%)$ & $\mathrm{SP}(\%)$ & $\mathrm{CP}(\%)$ & SP $(\%)$ \\
\hline Erythrina velutina & $53,42 \mathrm{aA}$ & $77,18 \mathrm{aA}$ & $85,66 \mathrm{aA}$ & $63,65 \mathrm{aA}$ \\
\hline Bowdichia virgilioides & $0,00 \mathrm{bA}$ & $0,00 \mathrm{bA}$ & $54,55 \mathrm{aA}$ & $9,09 \mathrm{bB}$ \\
\hline Sapindus saponaria & $90,41 \mathrm{aA}$ & $47,53 \mathrm{aB}$ & $86,85 \mathrm{aA}$ & $79,11 \mathrm{aA}$ \\
\hline Guazuma ulmifolia & $31,82 \mathrm{aA}$ & $11,90 \mathrm{bA}$ & $61,87 \mathrm{aA}$ & $7,17 \mathrm{bB}$ \\
\hline Lonchocarpus sericeus & $83,95 \mathrm{aA}$ & $58,33 \mathrm{aA}$ & $82,35 \mathrm{aA}$ & $83,75 \mathrm{aA}$ \\
\hline Machaerium aculeatum & $30,77 \mathrm{bA}$ & $0,00 \mathrm{bA}$ & $82,59 \mathrm{aA}$ & $44,44 \mathrm{aA}$ \\
\hline \multirow{2}{*}{ Média } & $48,40 \mathrm{~A}$ & $32,49 \mathrm{~A}$ & $75,64 \mathrm{~A}$ & $47,87 \mathrm{~B}$ \\
\hline & \multicolumn{2}{|c|}{$40,44 \mathrm{~B}$} & \multicolumn{2}{|c|}{$61,76 \mathrm{~A}$} \\
\hline
\end{tabular}

Médias seguidas pela mesma letra não diferem entre si, pelo teste de Scott-Knott a 5\% de probabilidade.

Letras minúsculas na vertical comparam as espécies, para cada protetor (CP/SP), em cada ambiente.

Letras maiúsculas na horizontal comparam protetor, para cada espécie, em cada ambiente.

Letras maiúsculas na horizontal comparam protetor, em cada ambiente.

Tabela 5 - Altura e diâmetro do colo das mudas, das espécies estudadas, até os 240 dias após a semeadura, nos dois subsistemas, localizados no Município de São Cristóvão, SE. CP - com protetor e ST sem protetor.

Table 5 - Height and base diameter of seedlings of studied species, 240 days after sowing, in the two subsystems, located in the city of Sao Cristovão, SE. CP - with physical protector; SP without physical protector.

\begin{tabular}{|c|c|c|c|c|c|c|c|c|}
\hline \multirow{3}{*}{ Espécies } & \multicolumn{4}{|c|}{ Altura $(\mathrm{cm})$} & \multicolumn{4}{|c|}{ Diâmetro do colo (mm) } \\
\hline & \multicolumn{2}{|c|}{ Subsistema pastagem } & \multicolumn{2}{|c|}{ Subsistema agricultura } & \multicolumn{2}{|c|}{ Subsistema pastagem } & \multicolumn{2}{|c|}{ Subsistema agricultura } \\
\hline & $\mathrm{CP}$ & SP & $\mathrm{CP}$ & SP & $\mathrm{CP}$ & SP & $\mathrm{CP}$ & SP \\
\hline Erythrina velutina & $59,41 \mathrm{aB}$ & $93,84 \mathrm{aA}$ & $80,47 \mathrm{aA}$ & $78,14 \mathrm{aA}$ & $27,24 \mathrm{aB}$ & $41,28 \mathrm{aA}$ & $36,79 \mathrm{aA}$ & $39,40 \mathrm{aA}$ \\
\hline Bowdichia virgilioides & $0,00 \mathrm{bA}$ & $0,00 \mathrm{bA}$ & $21,41 \mathrm{bA}$ & $3,75 \mathrm{bA}$ & $0,00 \mathrm{bA}$ & $0,00 \mathrm{bA}$ & $4,19 \mathrm{bA}$ & $0,89 \mathrm{bA}$ \\
\hline Sapindus saponaria & $19,42 \mathrm{bA}$ & $12,08 \mathrm{bA}$ & $26,26 \mathrm{bA}$ & $22,82 \mathrm{bA}$ & $4,00 \mathrm{bA}$ & $2,92 \mathrm{bA}$ & $5,42 \mathrm{bA}$ & $4,69 \mathrm{bA}$ \\
\hline Guazuma ulmifolia & $48,55 \mathrm{aA}$ & $18,70 \mathrm{bA}$ & $31,14 \mathrm{bA}$ & $5,41 \mathrm{bA}$ & $10,08 \mathrm{bA}$ & $4,26 \mathrm{bA}$ & $6,93 \mathrm{bA}$ & $1,17 \mathrm{bA}$ \\
\hline Lonchocarpus sericeus & $29,95 \mathrm{bA}$ & $19,18 \mathrm{bA}$ & $27,28 \mathrm{bA}$ & $25,69 \mathrm{bA}$ & 7,94 bA & $5,00 \mathrm{bA}$ & $6,92 \mathrm{bA}$ & $6,78 \mathrm{bA}$ \\
\hline Machaerium aculeatum & $3,71 \mathrm{bA}$ & $0,00 \mathrm{bA}$ & $5,17 \mathrm{bA}$ & $0,80 \mathrm{bA}$ & $1,12 \mathrm{bA}$ & $0,00 \mathrm{bA}$ & $1,86 \mathrm{bA}$ & $0,29 \mathrm{bA}$ \\
\hline \multirow{2}{*}{ Médias } & $26,84 \mathrm{~A}$ & $23,97 \mathrm{~A}$ & $31,96 \mathrm{~A}$ & $22,77 \mathrm{~A}$ & $8,40 \mathrm{~A}$ & $8,91 \mathrm{~A}$ & $10,35 \mathrm{~A}$ & $8,87 \mathrm{~A}$ \\
\hline & \multicolumn{2}{|c|}{$25,40 \mathrm{a}$} & \multicolumn{2}{|c|}{$27,36 \mathrm{a}$} & \multicolumn{2}{|c|}{$8,65 \mathrm{a}$} & \multicolumn{2}{|c|}{$9,61 \mathrm{a}$} \\
\hline
\end{tabular}

Médias seguidas pela mesma letra não diferem entre si, pelo teste de Scott-Knott a 5\% de probabilidade.

Letras minúsculas na vertical comparam as espécies, para cada protetor (CP/SP), em cada ambiente.

Letras minúsculas na horizontal comparam ambientes.

Letras maiúsculas na horizontal comparam protetor, em cada ambiente.

Revista Árvore, Viçosa-MG, v.36, n.2, p.237-245, 2012 
agricultura, em ambos os tratamentos apenas em $E$. velutina houve diferença significativa em comparação com as demais espécies.

Na análise das médias do diâmetro do colo das espécies estudadas não houve diferença significativa com relação às duas áreas avaliadas (Tabela 5). Para a média dos diâmetros entre as plantas das espécies, no subsistema pastagem E. velutina proporcionou os maiores valores nos dois tratamentos utilizados (com protetor e sem protetor), seguida de G. ulmifolia, $L$. sericeus e $S$. saponaria. O mesmo comportamento foi registrado no subsistema agricultura, com os menores resultados em campo para $M$. aculeatum e $B$. virgilioides.

Estatisticamente, não houve diferença significativa entre a ausência e uso de protetor físico no desenvolvimento em diâmetro das plantas das espécies estudadas, em cada ambiente. A exceção foi em E. velutina nos dois subsistemas, cujo maior valor foi obtido nas parcelas sem protetor, diferindo significativamente com relação ao uso do protetor físico no subsistema pastagem.

\section{DISCUSSÃO}

A avaliação das características físicas e fisiológicas das sementes é de fundamental importância para a análise da qualidade do lote das espécies utilizadas, podendo influenciar no processo de emergência de plântulas, sobrevivência e desenvolvimento das mudas em campo. Com base nos dados analisados, o comportamento das sementes é ortodoxo, uma vez que os teores de água foram próximos de 5-8\% (DAVIDE; SILVA, 2008). Elas ficaram armazenadas durante 12-18 meses em câmara fria e mantiveram-se viáveis até a implantação do experimento no campo, com exceção das sementes de M. aculeatum, nas quais o comportamento foi intermediário.

A emergência de plântulas e a sobrevivência das mudas em campo foram diferentes nos dois subsistemas avaliados, com melhores resultados no subsistema agricultura. Esse fator pode estar relacionado ao tipo de uso do solo e às suas características químicas e físicas, as quais apresentaram maior nível de fertilidade no subsistema agricultura. De acordo com Queiroz et al. (2008), os solos utilizados como pastagens, em geral, possuem baixa fertilidade natural, acidez elevada e má drenagem, apresentando baixa capacidade de suprir nutrientes, o que resulta em baixos níveis de produtividade.
As diferenças entre emergência de plântulas e sobrevivência das mudas entre as espécies podem estar relacionadas com o tamanho e massa específica das sementes, uma vez que sementes grandes dispõem de maior quantidade de reservas acumuladas para o desenvolvimento do eixo embrionário e estabelecimento das plântulas. Para Uhl et al. (1991), o sucesso da emergência de plântulas está diretamente relacionado ao tamanho das sementes, e sementes pequenas, menores que $0,5 \mathrm{~g}$, sofrem mais predação.

Em trabalho de recuperação de áreas naturais e degradadas na Amazônia Central, Camargo et al. (1998) utilizaram a semeadura direta, constatando que as espécies que tinham sementes grandes apresentaram boa emergência de plântulas e crescimento satisfatório, enquanto àquelas com sementes pequenas, que possuem poucas reservas, apresentaram baixa emergência de plântulas e não conseguiram se estabelecer em campo. Comportamento semelhante foi evidenciado por Ferreira et al. (2009) na implantação da semeadura direta em área de mata ciliar no Baixo São Francisco sergipano, onde a sobrevivência em campo das plântulas das espécies Cassia grandis, Hymenaea courbaril e Enterolobium contortisiliquum foi maior, devido ao tamanho de suas sementes.

Outro fator que pode ter contribuído para a emergência foi a utilização de tratamentos para a superação da dormência de sementes, os quais podem ter propiciado rápido estabelecimento das plântulas e, consequentemente, recobrimento mais rápido do solo.

O revolvimento do solo através da aração e da gradagem pode ter contribuído para a perda de sementes, principalmente nas parcelas sem protetor físico, devido à movimentação do solo, ocasionando o soterramento ou o arraste das sementes. Tal fato foi evidenciado no subsistema pastagem, no qual a emergência de plântulas das espécies G. ulmifolia, M. aculeatum, $L$. sericeus e $B$. virgilioides foi baixa, em comparação com as parcelas com protetores físicos. No subsistema agricultura, esse fato ocorreu nas sementes de $B$. virgilioides e M. aculeatum.

A mortalidade de $B$. virgilioides no subsistema pastagem foi de $100 \%$, mesmo com o uso do protetor físico. O mesmo comportamento foi presenciado para M. aculeatum nas parcelas sem protetor. Esse fato pode estar relacionado com as características edáficas

Revista Árvore, Viçosa-MG, v.36, n.2, p.237-245, 2012 
encontradas nessa área, com presença de erosão laminar e consequente soterramento ou arraste das plântulas em desenvolvimento, além de baixa infiltração.

Nos dois subsistemas, presenciou-se a ocorrência de lagartas e formigas nas plântulas em desenvolvimento, principalmente nas parcelas sem protetor. Verificaramse também o corte de algumas plântulas e pedaços de folhas no solo. De acordo com Mattei (1997), o ataque de formigas é preocupante na primeira fase de crescimento, prosseguindo até o final do primeiro ciclo vegetativo. Após esse período, com a realização do controle os danos podem ser reduzidos. Ainda segundo esse autor, caso os agentes causadores de perdas não sejam controlados, eles tendem a destruir as plantas de forma localizada, causando desuniformidade na área revegetada.

O crescimento em altura e diâmetro de plantas de E. velutina nos dois ambientes foi típico do grupo ecológico das espécies pioneiras, principalmente devido ao rápido crescimento em campo. Outro fator que também pode ter contribuído para o seu desenvolvimento foi o tamanho de suas sementes, uma vez que isso tem relação com o crescimento inicial das plantas, diminuindo esse efeito à medida que elas se desenvolvem. $\mathrm{O}$ desenvolvimento das plantas das demais espécies foi intermediário, comparando-se com aquele de E. velutina nas duas áreas.

Os diferentes comportamentos das espécies estudadas com relação à emergência, sobrevivência e desenvolvimento inicial das plantas fornecem informações específicas que podem auxiliar na escolha dessas espécies em trabalhos de recuperação florestal, por meio da semeadura direta.

\section{CONCLUSÕES}

O protetor físico foi eficaz no estabelecimento e desenvolvimento inicial das mudas de Erythrina velutina, Bowdichia virgilioides, Guazuma ulmifolia, Lonchocarpus sericeus e Sapindus saponaria.

O tamanho e massa específica das sementes das espécies estudadas influenciaram na emergência de plântulas e no estabelecimento inicial das mudas no campo.

As diferentes condições de sítios influenciaram na emergência de plântulas e na sobrevivência das mudas das espécies arbóreas implantadas por semeadura direta.

\section{REFERÊNCIAS}

AERTS, R. et al. Restoring dry afromontane forest using bird and nurse plant effects: direct sowing of Olea europaea ssp. cuspidate seeds. Forest Ecology and Management, v.30, n.1, p.23-31, 2006.

BARNETT, J. P.; BAKER, J. B. Regeneration methods. In: DURYEA, M. L.; DOUGHERTY, P. M. (Eds.). Forest regeneration manual. Dordrecht: Kluver Academic Publishers, 1991. p.35-50.

BRASIL. Ministério da Agricultura, Pecuária e Abastecimento. Regras para análise de sementes. Brasília: MAPA/ACS, 2009. 399p.

CAMARGO, J. L. C.; FERRAZ, I. D. K.; IMAKAWA, A. M. Estabelecimento de plântulas de espécies florestais por semeadura direta e longevidade do banco de sementes em áreas naturais e degradadas da Amazônia Central. In: HIGUCHI, N. et al. Pesquisas florestais para a conservação da floresta e reabilitação de áreas degradadas na Amazônia. Manaus: INPA, 1998. p.203-214.

DAVIDE, A. C.; FARIA, J. M. R.; BOTELHO, S. A. Propagação de espécies florestais. Belo Horizonte: CEMIG/UFLA/FAEPE, 1995. 45p.

DAVIDE, A. C.; SILVA, E. A. A. S. Sementes florestais. In: DAVIDE, A. C.; SILVA, E. A. A. S. (Eds). Produção de sementes e mudas de espécies florestais. Lavras: Universidade Federal de Lavras, 2008. p.11-82.

EMPRESA BRASILEIRA DE PESQUISA AGROPECUÁRIA - EMBRAPA. Sistema brasileiro de classificação de solos. Brasília: Embrapa Produção de Informação; Rio de Janeiro: Embrapa Solos, 1999. 412p.

FERREIRA, D. F. Sisvar-sistema de análise de variância. Lavras: Universidade Federal de Lavras, 2006.

FERREIRA, R. A. et al. Semeadura direta com espécies arbóreas para recuperação de ecossistemas florestais. Cerne, v.13, n.3, p.21-279, 2007.

FERREIRA, R. A. et al. Semeadura direta com espécies florestais na implantação de mata ciliar no Baixo São Francisco em Sergipe. Scientia Forestalis, v.37, n.81, p.37-46, 2009. 
KAGEYAMA, P. Y.; GANDARA, F. B. Recuperação de áreas ciliares. In: RODRIGUES, R. R.; LEITÃO FILHO, H. F. (Eds.). Matas ciliares: conservação e recuperação. São Paulo: EDUSP/FAPESP, 2004. p.249-269.

MATTEI, V. L. Preparo do solo e uso de protetor físico, na implantação de Cedrela fissilis V. e Pinus taeda L., por semeadura direta. Revista Brasileira de Agrociência, v.1, n.3, p.127-132, 1995a.

MATTEI, V. L. Importância de um protetor físico em pontos de semeadura de Pinus taeda L.

diretamente no campo. Revista Árvore, v.19, n.3, p.277-285, 1995b.

MATTEI, V. L. Avaliação de protetores físicos em semeadura direta de Pinus taeda L.

Ciência Florestal, v.7, n.1, p.91-100, 1997.

MATTEI, V. L.; ROMANO, C. M.; TEIXEIRA, M. C. C. Protetores físicos para semeadura direta de Pinus elliottii Engelm. Ciência Rural, v.31, n.5, p.775-780, 2001.
MELO, A. S. et al. Desenvolvimento vegetativo, rendimento da fruta e otimização do abacaxizeiro cv. Pérola em diferentes níveis de irrigação.

Ciência Rural, v.36, n.1, p.93-98, 2006.

OLIVEIRA-FILHO, A. et al. Estudos

florísticos e fitossociológicos em remanescentes de matas ciliares do Alto e Médio Rio Grande. Belo Horizonte: CEMIG, 1995. 27p.

QUEIROZ, D. S.; SALGADO, L. T.; FERNANDES, L. O. Recuperação de pastagens degradadas. Informe Agropecuário, v.29, n.244, p.55-65, 2008.

SANTOS JÚNIOR, N. A.; BOTELHO, S. A.; DAVIDE, A. C. Estudo da germinação e sobrevivência de espécies arbóreas em sistema de semeadura direta, visando à recomposição de mata ciliar, Cerne, v.10, n.1, p.103-117, 2004.

UHL, C. et al. Restauração da floresta em pastagens degradadas. Ciência Hoje, v.13, n.76, p.23-31, 1991. 
